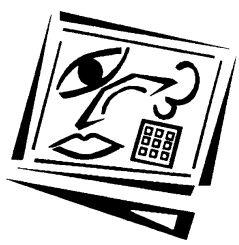

\title{
Using blogging to promote clinical reasoning and metacognition in undergraduate physiotherapy fieldwork programs
}

\author{
Shuyan Melissa Tan, Richard K. Ladyshewsky and Peter Gardner
} Curtin University of Technology

\begin{abstract}
This qualitative study investigated the impact of using blogs on the clinical reasoning and meta-cognitive skills of undergraduate physiotherapy students in a fieldwork education program. A blog is a web based document that enables individuals to enter comments and read each others' comments in a dynamic and interactive manner. In this study, final year physiotherapy students were randomly allocated to group blogs to share their reflections on their own and their peers' clinical practice. Blogging was used to help students reflect and focus on professional and evidence based practice within a supportive peer assisted learning environment. The text within each of the blogs was qualitatively analysed against concepts in the literature describing specific types of clinical reasoning and metacognition. A range of clinical reasoning typologies were found to exist in the blogs. Most notable were ethical, interactive and procedural reasoning along with evidence of metacognition. Blogging was found to be a good strategy for promoting clinical reasoning and metacognition in fieldwork education.
\end{abstract}

\section{Introduction}

This paper explores how the use of peer assisted learning, through the use of blogging, can afford opportunities and support for the development of clinical reasoning and metacognition in undergraduate physiotherapy students. A brief outline of clinical reasoning is provided, along with an explanation of metacognition and how this latter concept supports the former. This is followed by a brief explanation of peer assisted learning and blogging and how these educational methodologies can be leveraged through a blended learning strategy into a fieldwork program.

One of the goals of physiotherapy education is to produce competent practitioners. The importance of clinical reasoning in building this competence is critical and is evidenced by a range of research in this area (Jensen, Gwyer, Hack \& Shepard, 1999; Jones, 2003; Refshauge \& Higgs (2000); Jones, Jensen \& Edwards, 2008). Physiotherapists are required to exercise their clinical reasoning skills not only in diagnosing movement disorders but also in managing the patient's problem by understanding contributing factors, precautions and contraindications to physical examination, treatment and prognosis (Jones 1992). Novice clinicians, such as physiotherapy students, generally use a form of clinical reasoning termed hypotheticodeductive reasoning. This form of reasoning involves cue acquisition, hypothesis generation, cue interpretation and hypothesis evaluation (Umphred, 1995). The hypothetico-deductive reasoning process is a very biomedical model of clinical reasoning. Hence, other forms of clinical reasoning are also identified in the literature, 
which complement this biomedical form of reasoning. These other forms of clinical reasoning are described in Table 1 and include: ethical reasoning (Swisher, 2002), collaborative reasoning (Thornquist, 2001), interactive reasoning (Fleming, 1991), procedural reasoning and diagnostic reasoning (Jones, Jensen \& Rothstein, 2000). This paper will focus on the ethical, interactive and procedural aspects of the clinical reasoning process.

Clinicians invariably apply all of these clinical reasoning strategies in their daily practice to inform their therapeutic decisions (Higgs \& Jones, 2008). With physiotherapy students, however, these clinical reasoning strategies are often being applied for the first time with novel clinical cases. The potential for clinical reasoning errors at this stage of practice development is, therefore, common (Boshuizen \& Schmidt, 1992, 2008). Hence, strategies which support physiotherapy students to enhance the rigour of their clinical reasoning and metacognition are critical for entry level competence and work readiness.

Metacognition has also been identified as a critical component of clinical reasoning. Metacognition is the integrative element between knowledge and cognition (Higgs \& Jones 2008). Higgs (1988) suggests that meta-cognitive skills can be thought of as higher order processing skills that involve thinking about one's own thoughts and considering how much one knows and does not know. Metacognition enables clinicians to heighten attention to their clinical reasoning and decision making processes to augment their understanding of clinical problems. It is also an important part of reducing clinical reasoning errors (Higgs \& Jones 1995). As a result, strategies that support students to develop their meta-cognitive skills are critical for the development of entry level competence.

Peer assisted learning and reflective practice are two methods that have demonstrated utility in improving clinical reasoning and metacognition. Research has demonstrated that peer assisted learning is an effective strategy to improve achievement and has shown positive impacts across many age groups, cultural groups and ability levels (Johnson et al. 1981; Topping 1992). More recently, the use of peer assisted learning has been found to support the development of sound clinical reasoning skills (Schmidt \& Boshuizen, 1993; Ladyshewsky, 1993, 1995, 2002, 2006; Higgs, 1992; Refshauge \& Higgs 2000). Refshauge and Higgs (2000) describe an experiential learning framework that employs peer assisted learning, as one that allows the learners to relay their experiences, discuss their reflections and make conclusions after considering their own and their peers' inputs before finally forming an improved view of the experience. The discussions that peers engage in about their clinical practice provides an environment for positive cognitive conflict to occur (Johnson, Johnson \& Smith 1998). Positive cognitive conflict arises when peers discover differences in their knowledge base. This disequilibrium regarding the discrepancy in knowledge between peers encourages them to initiate strategies to critically evaluate their understanding of the issue in question. These actions heighten metacognition, fuel further investigation, and hopefully afford opportunities to further develop the clinical reasoning process.

The development of Web 2.0 software has created opportunities to integrate many of the concepts described to this point into an educational methodology that can support students during their clinical fieldwork. Tertiary education institutions are faced with ever expanding opportunities to integrate social media and technologies in teaching, learning and assessment (McLoughlin \& Lee, 2010). Web 2.0 software provides tools, which in turn, creates opportunities to increase the level of experiential learning, 
reflective practice and peer engagement against a background of social and cognitive support. With this in place, opportunities for creating critical cognitive conflict to occur are enhanced. This tool is called blogging and is a form of information communications technology.

A blog is short for web log (Jacobs 2003) and is written by individuals or groups of people on the world wide web. It is analogous to an online diary or journal that has open access. A person who contributes written material to a blog is called a blogger. A blog can focus on any topic and is frequently updated in reverse chronological order so the most recent entry appears first. Blogs allow readers to leave written comments as well as links to other websites, upload photos and sound files. Blogs are one of the newer directions in e-learning and e-education (Mouhtouris, 2006; Ellison \& Yu, 2006) as they provide creative spaces for learners to co-produce ideas and knowledge (Hiler, 2002; Allen, 1999). Hence, blogging can be used to integrate groups of learners into a cohesive space where they can explore issues of relevance to their learning and practice. It also creates an environment where peers, under the guidance of an academic moderator, can engage in self-regulated discovery learning, against a backdrop of clear guidelines and support, to ensure their learning is scaffolded in a way to achieve desired educational outcomes (McLoughlin \& Lee, 2010).

Ladyshewsky and Gardner (2008) explored the effectiveness of blogging and peer assisted learning to encourage reflective practice in groups of physiotherapy students during their clinical fieldwork. This pilot project established that students had a positive experience with blogging as it was a simple and convenient tool that allowed them to learn from the knowledge and experience of other students. Blogging was found to create interesting possibilities for physiotherapy education programs interested in using peer assisted learning strategies to elevate the depth and rigour of clinical reasoning in their student populations. It expands the scope of fieldwork education by offering a blended learning design which is student centred (Koohang, 2009). Blended learning incorporates face to face and online learning technologies. Whilst there have been a few studies on blogging as a tool to support clinical reasoning (Boulos, Maramba, and Wheeler 2006; Chesanow 2004; Maag 2005; Mongkolwat et al. 2005; Plutchak 2005; Sauer et al. 2005) there is little evidence to suggest how it actually influences clinical reasoning and metacognition. Hence, the objective of this research was to determine the impact of blogging on the clinical reasoning and metacognition of physiotherapy students during their clinical fieldwork.

\section{Method}

To study the impact of blogging on the clinical reasoning of physiotherapy students, a qualitative methodology was applied. For this research, well established definitions of clinical reasoning, focusing predominately on biomedical reasoning, were derived from the literature and used to analyse the content of the blogs. The specific research question reported on in this research therefore was, "how does blogging support the clinical reasoning skills of physiotherapy students during their clinical fieldwork?"

\section{Participants}

Participants were 83 full time undergraduate students enrolled in a four year Bachelor of Science (Physiotherapy) degree program. The participants were in their final year of the program and spent both semesters (February-May) and (July-December) in full time clinical placements. Each placement was four to five weeks in duration. 
To investigate the potential of blogging in promoting the clinical reasoning and metacognitive skills of these final year students, a total of 8 blogging groups were set up by the fieldwork program director which captured all 83 students of the students in the program. Assignment of students to each blog was random, using a random number generator, with each blogging group having a total of 9 to 10 students. Five of these blogging groups were randomly selected from the group of 8 for analysis with respect to clinical reasoning content. A total of 45 final year students in the end had their blogging posts subjected to analysis and coding.

All physiotherapy students, or bloggers as they are called, attended a practical session to familiarise themselves with the blogging software. They were provided with written guidelines regarding the technical aspects of blogging as well as the requirements for making specific postings on the website. The guidelines included information about patient and clinical facility confidentiality (i.e. using pseudonyms to describe patients, staff and agencies), blogging etiquette and plagiarism. The groups were taken through the process of setting up their blog with the fieldwork program director who served as the administrator of each of the blog sites. Students were given examples of previous students' posts in order to illustrate the depth of reflection necessary and the types of issues that may be included in reflections. An academic staff member was also assigned the role of moderator for each blog group. Their role is discussed later in this paper. All blogs, in this case, were password protected and each blog was available only to other members of the same blogging group as well as the Academic Coordinator of the unit of study for purposes of grading.

\section{Blogging}

The software that students used for blogging was available online at http://www.blogger.com/. An external site was chosen because of its simplicity, it provided students with exposure to real world social networking technology, and was less constrained than a University sponsored learning management system. The open access format of the software also meant students could continue blogging after their course if they desired.

Physiotherapy program have to provide evidence of reflective practice in their curriculum in order to meet professional standards. Hence, the program's objective for using blogging was to demonstrate curricular practices that provided students with opportunities to reflect on issues of professional and evidence based practice. It also appeared to provide a medium to promote peer assisted learning strategies amongst students to support their clinical reasoning and metacognition skills.

Students were instructed to highlight experiences that might change their future approaches to clinical practice. The requirement was for students to post at least one original reflection and to comment on two of their group members' original posts each week for the duration of the clinical placement. In order to encourage engagement, the students were assessed on fulfilling the minimum criteria of number of posts, whether the entries were submitted on time, and on evidence of sufficient depth of reflection in the entries. This was graded as a Pass or a Fail.

As noted earlier, an academic member of the School of Physiotherapy staff was assigned the role of moderator for each group and thereby acted as the group's facilitator and assessor. However, it was explained clearly to students that the staff members' role was to respond only when students strayed from the topic or when the 
staff member deemed appropriate. All students were required to contribute to and participate in reflective practice discussions within their blog group for the duration of their clinical program.

\section{Data analysis}

The blogs were extracted from the web and converted into text files for loading into NVivo 7.0, which is a software tool that can be used for management and analysis of qualitative data (Gibbs, 2004). Coding and analysis of the five blogging groups' content continued until such time that theoretical saturation was noted. Theoretical saturation, in qualitative research (Charmaz, 2006), occurs when ongoing interrogation of the data yields no further concepts.

The data consisted of 239 blogs (primary postings) and 261 blog comments (responses to primary postings), these were conflated to represent a total of 500 blog postings. Technically the primary posting is a blog as it represents the views of the blogger. The comment in return, is merely a response and not technically a blog. However, for the purposes of this research, the postings and comments were conflated as they often contained an integrated and rich view of the students' clinical reasoning and their meta-cognitive perspectives. To analyse these separately would disjoint the meaning contained within these integrated conversations.

Only 475 blog postings were actually coded by the investigators as they contained items of meaning relevant to the research question in this paper, and to other concepts not reported in this paper. The reflective blogs written by the physiotherapy students were coded according to concepts described in the literature that relate to clinical reasoning. Other codings were also applied to reflective practice and peer assisted learning but are not reported or discussed in this paper.

A plausibility and congruency check of the main investigator's coding practices was undertaken with the support of the two co-investigators. The two co-investigators reviewed five pages of coding to ensure accuracy, consistency and plausability of the primary investigator's coding. Any ambiguities in coding between investigators were discussed, reviewed and amended where necessary. With this exercise, 95 per cent agreement in coding practices between the primary and co-investigators was achieved. This plausibility and congruence check was then followed by coding of the full data set by the primary investigator.

The codes or terms that were used to analyse the data were taken directly from the literature where well established definitions of clinical reasoning are available. The blogs were coded against these definitions on clinical reasoning to help with the analysis in answering the research question. Table 1 provides definitions of some biomedically oriented clinical reasoning typologies, as drawn from the literature, which were applied to the data set in this research.

As noted earlier, the research question was interested in determining if blogging, as a tool, affords students with an opportunity to further develop their clinical reasoning and meta-cognitive skills when on their fieldwork. A total of 109 blog postings from the full data set of 475 blog postings were coded using clinical reasoning definitions extracted from the literature. These same 109 blog postings were then coded for evidence of meta-cognition using definitions that describe reflective action in a peer assisted learning context (Green, 2005). Green describes five spaces of influence that 
Table 1: Some types of clinical reasoning codes

\begin{tabular}{|c|c|}
\hline Codes & Definitions \\
\hline $\begin{array}{l}\text { Ethical reasoning (Edwards, } \\
\text { Jones et al (2004) }\end{array}$ & $\begin{array}{l}\text { Reasoning of ethical and practical dilemmas that impinge on } \\
\text { both the conduct of intervention and its desired goals, and the } \\
\text { resultant action toward their resolution. }\end{array}$ \\
\hline $\begin{array}{l}\text { Interactive reasoning (Fleming, } \\
\text { 1991) }\end{array}$ & $\begin{array}{l}\text { Face to face interaction between the clinician and the patient } \\
\text { that allows rapport to be built such that clinicians will be able to } \\
\text { know them personally, gain insights into their feelings about } \\
\text { treatment and understand the contexts in which their problems } \\
\text { exist. }\end{array}$ \\
\hline $\begin{array}{l}\text { Diagnostic reasoning (Jones, } \\
\text { Jensen et al. 2000) }\end{array}$ & $\begin{array}{l}\text { Investigates patient's disability and related impairments, the } \\
\text { pain mechanism, structures involved, pathophysiology and } \\
\text { contributing factors to the maintenance and development of the } \\
\text { dysfunction. Also the collective term for hypothetico-deductive } \\
\text { reasoning and reasoning using pattern recognition. }\end{array}$ \\
\hline $\begin{array}{l}\text { Procedural reasoning (Jones, } \\
\text { Jensen et al 2000) }\end{array}$ & Making decisions in treatments. \\
\hline $\begin{array}{l}\text { Collaborative reasoning } \\
\text { (Edwards, Jones, Higgs et al. } \\
\text { 2004) }\end{array}$ & $\begin{array}{l}\text { Collaborative reasoning is about setting goals with patients and } \\
\text { nurturing a collaborative approach in working towards the } \\
\text { goals. }\end{array}$ \\
\hline $\begin{array}{l}\text { Hypothesis generation (Doody } \\
\text { \& McAteer 2002) }\end{array}$ & $\begin{array}{l}\text { Using cues or cue generation interpretation as a basis for } \\
\text { making an assumption. }\end{array}$ \\
\hline $\begin{array}{l}\text { Hypothesis evaluation (Doody } \\
\text { \& McAteer 2002) }\end{array}$ & $\begin{array}{l}\text { Formulation of a judgment as to the value of evaluation the } \\
\text { hypothesis. Decision as to the most plausible hypothesis(es). }\end{array}$ \\
\hline
\end{tabular}

take place during learning with others, three of which are highly aligned to metacognition. These three spaces are: spaces of explicit discourse; spaces of learning; and spaces of practice development. Spaces of explicit discourse refer to spaces in which a learner's initial private thoughts are explicitly laid out in writing (in this case), thus enabling learners to see things from a different perspective. Spaces in which learners engage with content knowledge relevant to their learning are termed spaces of learning. Content examples will be brought up and the cycle of growth within these spaces of learning is fed by opportunities for critical feedback. This can be illustrated when peers challenge the learners about their own ideas. Spaces of practice development are spaces where the process of actual practice occurs. It is assumed that variation of practice or processes are acknowledged and discussed.

\section{Findings and discussion}

The students demonstrated that they applied a range of clinical reasoning skills, in keeping with definitions selected in the literature. The range of clinical reasoning categories are described in Table 2 and include: collaborative; diagnostic; ethical; interactive; and procedural reasoning. Procedural, ethical and interactive reasoning were the most frequently blogged forms of clinical reasoning strategies and are discussed in more detail. These three categories also proportionately generated the most discussion (about $90 \%$ of the blogs on clinical reasoning) out of all the other clinical reasoning types.

\section{Ethical reasoning}

A large number of the blogs focussed on ethical reasoning and demonstrated a range of issues brought up by the students in the blogs. The numbers of blogs according to the type of ethical dilemma in question, and its proportion out of all the ethical 
Table 2: Clinical reasoning categories applied by students in the blogs

\begin{tabular}{|l|c|c|}
\hline $\begin{array}{c}\text { Type of clinical } \\
\text { reasoning }\end{array}$ & $\begin{array}{c}\text { Number } \\
\text { of blogs }\end{array}$ & $\begin{array}{c}\text { \% of all clinical } \\
\text { reasoning blogs }\end{array}$ \\
\hline Pattern recognition & 0 & 0 \\
\hline Collaborative reasoning & 3 & 2.75 \\
\hline Diagnostic reasoning & 6 & 5.50 \\
\hline Ethical reasoning & 32 & 29.36 \\
\hline Interactive reasoning & 26 & 23.85 \\
\hline Procedural reasoning & 42 & 38.54 \\
\hline Total & 109 & 100 \\
\hline
\end{tabular}

dilemmas, is described in Table 3. Issues that arose included confidentiality, choice to treat, observing cultural differences, discrimination of the poor, carrying out an effective treatment, inappropriate patient behaviours, resource limitations and relationships with other health professionals. Resource limitations and choice to treat were the two ethical dilemmas that generated almost half of all the blogs on ethical reasoning.

Table 3: Ethical dilemmas in blogs

\begin{tabular}{|l|c|c|}
\hline \multicolumn{1}{|c|}{ Ethical dilemmas } & $\begin{array}{c}\text { Number } \\
\text { of blogs }\end{array}$ & $\begin{array}{c}\% \text { of all ethical } \\
\text { reasoning blogs }\end{array}$ \\
\hline Resource limitations & 9 & 28.12 \\
\hline Choice to treat & 7 & 21.88 \\
\hline Inappropriate patient behaviour & 5 & 15.63 \\
\hline Relationship with other health professionals & 5 & 15.63 \\
\hline Cultural sensitivity & 2 & 6.25 \\
\hline Effective treatment & 2 & 6.25 \\
\hline Discrimination (poor) & 1 & 3.12 \\
\hline Confidentiality & 1 & 3.12 \\
\hline Total & 32 & 100 \\
\hline
\end{tabular}

An example of choice to treat is illustrated in the quotation below, in which a patient is refusing treatment. In ethical reasoning (Edwards, Jones et al (2004) a dilemma involving the choice to treat a patient, or not, positions the student between the concepts of beneficence versus autonomy of the patient. The student in this example decides to apply the concept of non-maleficence by providing the patient with all the necessary information to exhaust the options before observing the concept of patient autonomy. However, the student seeks the input of the blog group for advice in this ethical dilemma. According to Gillon (1994), the concept of beneficence is described as the responsibility to do good to those we work for and non-maleficence as the opposite which is not to do harm.

.... am on my Cardio placement at the moment and have come across my first patient who flatly refuses to get out of bed, no matter how much persuasion is used.... My question is how much do you really push patients, if they are feeling really unwell and state that when they do get up they feel nauseus etc, should we continue to keep pushing them to do something they don't want to do... As long as we give them all the information, the benefits etc, then $i$ think pushing a patient to get mobile should have its limits.

Another example is a student faced with the ethical dilemma of resource allocation. In this example they acknowledge that the hospital cannot afford to accommodate this client, yet, the student is bothered by the fact that it conflicts with the concept of 
justice. In this case, the student is able to identify the ethical dilemma but is unable to come to a conclusion and seeks clarification from the blog group.

These patients often seem to be in and out of hospital with various issues. I came across one who had intentionally overdosed three days after being released from a hospital (following a similar admission). They had been released to attend out-patients appointments, but as it turns out was perhaps not ready for this. My question is whether there is anything else that can be done to manage these difficult situations? They obviously cannot be kept in hospital indefinitely but discharging them to their own devices after such a short period of time seems both ineffective and perhaps irresponsible?

\section{Interactive reasoning}

Approximately a quarter of the blogs (23.9\%) could be linked to the concept of interactive reasoning (Fleming, 1991). Through interactive reasoning, students gained insights into patient treatment. When analysing the blogs, a few groups of patients were the subject of interactive reasoning. These groups included geriatric and paediatric client groups, young adult males, indigenous populations and clients with communication difficulties. Below is an example of a blog discussion regarding a paediatric client base that illustrates the application of interactive reasoning, as the conversation embeds some strategies about treating children. Student B reaffirms the insights of the other two students (S, F). A contribution by one of the other students (F) adds to the pool of insights.

B: ... I have unintentionally started my sentences with "Can you..." and unsurprisingly the child usually will not do it by saying "no I can't" or "I don't want to". Working with children requires you to take a more authoritative approach, while still trying to make the environment fun and friendly.

S: I have found working with children very different to any other patient population. The best way to get them to do things is using an authoritative nature but making the treatment session fun.

F: I agree as well S and B... and engage the parent in the session as much as you can, if the parent and yourself can work collectively and as a team I think that is very positive, however, not all mothers / fathers are those that you want around in your treatment zone (i.e. the insanely nagging and super ott [over the top] safety conscious parents) Children definitely respond to ' hey show me how you do this???' asking them questions like 'what do you think is wrong with this picture for example, the picture of you performing an exercise poorly is an effective tool engaging the child and seeing how they analyse and reflect particular situations. It is all about the 'show me this' and 'lets be frogs and jump around' ' what happens if you were a lion...what would he sound like?

A second example of interactive reasoning is described using a geriatric population and issues around motivating elderly clients about treatment.

E: ... no matter how often I tell them how important it is to do their exercises, or how many explanations I give them on why I need to know about their home life, it just doesnt seem to make much difference...... just so hard to push someone when they state to me that they have only just got back into bed and the nurses have tucked them up really well and everything, ... But at the moment i've found that negotiating with them works quite well.

S: I am having similar problems ... in motivating some elderly patients. I have found it quite useful to create a "long term goal of treatment" with the patients. For example, 
with the elderly, getting them back to walking for a period of time by themselves, or reducing their risk of falling. If you constantly remind them that without completing the exercises, they will not be able to reach this optimal goal. I have found this to be a great motivator.

A: ... the hardest part of my day was getting my patients out of bed and down to the gym or off for a walk. All of my patients had a long term goal of getting out of hospital but when it came to the moment I walked through the door their motivation levels dropped through the floor. I found that meal times are very handy if there is a separate dining hall as you can arrive half an hour before lunch or dinner and take the long way to the dinning hall via the gym.

\section{Procedural reasoning}

Procedural reasoning (Jones, Jensen \& Rothstein, 1995) was the most frequent form of clinical reasoning that was evidenced in the blogs $(38.5 \%)$. This is not surprising given that many of these students are applying treatments for the first time and need a lot of support. Through blog discussions focused on procedural reasoning, students gained insights about their treatment and practice. The following quotations illustrate an example of a blog that is clearly about procedural reasoning and involves whether physiotherapy intervention is appropriate in a patient with a compromised neurological status.

$\mathrm{H}$ : We need to recognise that our treatment already indicated that it may have a detrimental effect on neuro status...this is of greater concern. Physio at the present is not indicated however the patient will be monitored and when more neurologically stable, we will intervene.

$\mathrm{K}$ : That is so true, that's why clinical reasoning is so important when we are on prac/at work. The knowledge we have is quite specific and sometimes we miss the whole picture. It is always a good idea to take a step back and look at a patient globally.

In this next example of procedural reasoning, whilst there is some ethical reasoning present, the student (D) applies procedural reasoning to ambulation of an abusive patient on oxygen therapy, with suggestions from student (L).

D: I find it hard to ignore because I am unwilling to get him up and walking on oxygen if he is going to become abusive halfway down the corridor. He is too unpredictable to be considered safe to walk on oxygen and it wouldn't be safe for me because you have to be close to him when walking. On the other hand this is pretty much the only treatment I can do for him so if I don't do it he gets no physio intervention at all, which he badly needs.

L: ... Maybe you can explain to him the potential dangers of what could happen while he's on oxygen so he is more consistent with his behaviour and maybe you could set some chairs up along the way and if he flies of the handle at least you could ask him to sit and have a rest while he's not in the best mood? ... Also maybe get another physio to come with you so you are not alone if a sticky situation arises.

\section{Metacognition}

As noted earlier, metacognition is an important component of clinical reasoning as it guides the students into considering what they know and what they don't know, and the action(s) required that inform practice. Table 4 provides an example of how the blog postings facilitated the application of metacognition to explore individual practice. Of 109 blogs that were considered to contain clinical reasoning, 66 were coded 
as displaying evidence of metacognition using the terms defined by Green (2005) on learning spaces, namely: spaces of learning; spaces of explicit discourse; and spaces of practice development. These three spaces are reported collectively, using the text where ethical, interactive or procedural reasoning took place. Within these clinical reasoning conversations, the frequency and percentage of meta-cognitive discussions can be seen. Interactive reasoning appeared to fuel the most amount of meta-cognitive activity although ethical and procedural reasoning were still influenced by the use of metacognition. This is not surprising, given that interactive reasoning is probably the most subjective area of reasoning given its definition in Table 1. Hence, it is more conducive for meta-cognitive discussion as it is about gaining insight and understanding the context of the patients and their impairments.

Table 4: Type of clinical reasoning with metacognition

\begin{tabular}{|l|c|c|c|c|}
\hline $\begin{array}{c}\text { Type of clinical } \\
\text { reasoning }\end{array}$ & $\begin{array}{c}\text { Number of blogs } \\
\text { displaying } \\
\text { metacognition }\end{array}$ & $\begin{array}{c}\text { Number of blogs } \\
\text { with no evidence } \\
\text { of metacognition }\end{array}$ & $\begin{array}{c}\text { \% of blogs } \\
\text { displaying } \\
\text { metacognition }\end{array}$ & $\begin{array}{c}\text { \% of blogs with } \\
\text { no evidence of } \\
\text { metacognition }\end{array}$ \\
\hline Ethical reasoning & 19 & 13 & 61.3 & 38.7 \\
\hline Interactive reasoning & 22 & 4 & 84.6 & 15.4 \\
\hline Procedural reasoning & 25 & 17 & 59.5 & 40.5 \\
\hline Total & 66 & 34 & & \\
\hline
\end{tabular}

The following two examples illustrate how students engaged in a personal cognitive conflict, try to come to terms with their clinical practice. The coding term, as defined in the literature by Green (2005), is provided in brackets to illustrate the meta-cognitive category.

\begin{abstract}
W: ... patient was scheduled to be discharged the next day after his op, however due to his non-compliance I informed the medical team of his behaviour and they've decided to keep him for longer. I don't plan to discharge him anytime soon however he is costing the hospital too much per day and he will eventually have to be discharged. It has already been assumed that he will return with another injury..... there is only so much we can do to prevent future injuries. As long as we document carefully in the notes and inform the medical team then I believe we have done our part. (space of explicit discourse)
\end{abstract}

$\mathrm{K}: \ldots$ he was unwilling to participate and the only thing he wanted was to kick or punch me. I wasn't quite sure what to do so I went back to consult my supervisor ... she suggested since the patient was not doing anything apart from kicking or punching, I might have to integrate these two movements into his session ... knee extension in sitting, I have to ask him to 'kick my hand'. To be honest, this method worked for that patient yet I was thinking: Would this encourage patient to develop an aggressive manner towards other medical staff? Is it an appropriate method to treat your patient while hospital has emphasised on the importance of 'zero-tolerance' policy. (space of practice development)

The peer assisted learning environment, made possible by blogging, appeared to be of benefit to the students. Peers responded to peers in situations where a student was only able to display a set level of meta-cognitive skill. Similarly, students felt empowered to respond when there was evidence of a lack of insight or knowledge. This student support, afforded through the blogging tool, impacted on the students' meta-cognitive and clinical reasoning skills. Opportunities for positive cognitive conflict, through discussion in the blogs, facilitated cognitive development (Vygotsky, 1978; Johnson, Johnson \& Smith, 1998) and opportunities through the debates that emanated on the topic. 
The blogging tool, therefore, provided physiotherapy students with opportunities to explore a range of clinical reasoning dilemmas, in a safe space, even though they were dispersed across a range of facilities and changed locations every four to five weeks. The use of the web enabled the students to maintain connections with their peers and use the blogs to support them in their fieldwork practice. This promoted the development of metacognition at both an individual and collective level. The fact that the blog group remained the same, and developed a level of comfort and trust as the weeks progressed, helped to promote self disclosure and conversations that would support and scaffold developments (McLoughlin \& Lee, 2010) in clinical practice.

The blogging particularly aided the development of clinical reasoning in the areas investigated in this study, namely, ethical, interactive and procedural reasoning, all important components of effective thinking in competent physiotherapists (Edwards, Jones, Carr et al. 2004). Academic programs are often required, as part of their curriculum, to build in reflective practice approaches that promote and develop clinical reasoning and support lifelong learning strategies. The use of blogging appeared to provide a rich format for students to continually evaluate and practice their reasoning and would be appropriate for any fieldwork program to implement. It also provides a medium for students to explore practice issues that they do not feel comfortable discussing with their supervisors, because of evaluation pressure. It also reduces the burden on clinical supervisors as students could offer valuable support and suggestions to one another.

Not every blog, however, could be coded against a clinical reasoning category, despite the provision of guidelines. Hence students also used the blogs for other discussions not related to the specific guidelines. This in itself is not a problem, as these peripheral conversations help to build community and trust in the group, a pre-requisite for a successful peer assisted learning experience. This sense of learner safety, in turn, promotes self disclosure about difficulties or issues students may be experiencing in their practice.

The requirement of a single posting and two responses, however, may only encourage participation to a minimum. This potentially reduces the impact of the peer assisted learning and blogging experience. Insisting that students provide more comments may have increased learner engagement and involvement. To promote further engagement with the activity, additional strategies are needed which involve applying more cooperative learning principles (Johnson et al. 1981; Topping 1992). Some of these strategies include joint interdependence and group rewards. Some planned future strategies, therefore, include marking only a random set of blog postings within the blog group and providing the entire group with a single mark (group reward). This may encourage deeper engagement with the blogs because the entire group is responsible for generating their best effort (joint interdependence). This strategy uses assessment to drive the learning and engagement with the activity, a term called constructive alignment (Biggs 2003). It also promotes individual accountability because participants realise they all must play a part in the group's success (group reward). Selecting the best blogging group out of the entire cohort (in terms of overall mark received) and awarding a reflective practice prize may be another incentive as intergroup competition often encourages more intra-group effort (Johnson et al. 1981; Qin, Johnson \& Johnson, 1995). 


\section{Conclusions}

This paper complements earlier research on the use of information communication technology in building professional practice which offers guidelines on the effective use of blogging in clinical fieldwork programs (Ladyshewsky \& Gardner, 2008). This research indicates that blogging is a tool that can be used to promote learner self discovery and to assist self-regulated learning in fieldwork education programs. By having clear guidelines in place which help to scaffold the learners' efforts towards expected learning outcomes, a focus on the learners' clinical reasoning and metacognitive skills were evident. Health science programs continue to seek improvements in ways to produce competent and reflective practitioners. Recommendations for future practice could include applying this approach to reflective practice and reasoning to other health science and professional disciplines, and to also integrate further cooperative learning strategies to see if this enhances learner involvement and engagement. For example, the greater use of strategies that involve group reward, joint interdependence and inter-group competition. This research provides evidence that blogging can be a viable learning tool to facilitate clinical reasoning and metacognitive growth through the use of peer learning strategies in fieldwork education programs.

\section{References}

Allen, M. (1999). Don't be a troll! Using the Internet for successful higher education. Paper presented at Higher Education '99, Sydney, March.

Biggs, J. (1988). The role of metacognition in enhancing learning. Australian Journal of Education, $32(2), 127-138$.

Biggs, J. (2003). Teaching for quality learning at university. 2nd ed. Buckingham: Open University and Society for Research into Higher Education.

Boshuizen, H. \& Schmidt, H. (1992). On the role of biomedical knowledge in clinical reasoning by experts, intermediates and novices. Cognitive Science, 16, 153-184.

Boshuizen, H. \& Schmidt, H. (2008). The development of clinical reasoning expertise. In J. Higgs, M. Jones, S. Loftus \& N. Christensen (Eds), Clinical reasoning in the health professions. pp.113122. London: Butterworth Heinemann Elsevier.

Boulos, M., Maramba, I. \& Wheeler, S. (2006). Wikis, blogs and podcasts: A new generation of Web-based tools for virtual collaborative clinical practice and education. BMC Medical Education, 6(41). http: / / www.ncbi.nlm.nih.gov/pmc/articles/ PMC1564136/

Charmaz, K. (2006). Constructing grounded theory: A practical guide through qualitative analysis. London: Sage Publications Ltd.

Chesanow, N. (2004). Doctors and "blogs". Journal of Medical Economics, 81(16), 33-37.

Doody, C. \& McAteer, M. (2002). Clinical reasoning of expert and novice physiotherapists in an outpatient orthopaedic setting. Physiotherapy, 88(5), 258-268.

Edwards, I., Jones, M., Carr, J., Braunack-Mayer, A. \& Jensen, G. (2004). Clinical reasoning strategies in physical therapy. Physical Therapy, 84(4), 312-330.

Edwards, I., Jones, M., Higgs, J., Trede, F. \& Jensen, G. (2004). What is collaborative reasoning? Advances in Physiotherapy, 6, 70-83. 
Ellison, N. \& Wu, Y. (2006). An empirical test of blogging in the classroom. HigherEd BlogCon. [verified 7 May 2010] http: / / www.higheredblogcon.com/index.php/an-empirical-test-ofblogging-in-the-classroom/

Gibbs, G. (2004). What is qualitative analysis? In Qualitative data analysis: Explorations with Nvivo, 1-15. New York: Open University Press.

Gillon, R. (1994). Medical ethics: Four principles plus attention to scope. British Medical Journal, $309,184$.

Green, P. (2005). Spaces of influence: A framework for analysis of an individual's contribution within communities of practice. Higher Education Research \& Development, 24(4), 293-307.

Higgs, J. (1992). Developing clinical reasoning competencies. Physiotherapy, 78(8), 575-579.

Higgs, J. \& M. Jones. (1995). Clinical reasoning. In J. Higgs \& M. Jones (Eds), Clinical reasoning in the health professions. pp.3-20. Oxford: Butterworth-Heinemann.

Higgs, J. \& Jones, M. (2008). Clinical decision making and multiple problem spaces. In J. Higgs, M. Jones, S. Loftus \& N. Christensen (Eds), Clinical reasoning in the health professions. pp.3-17. Sydney: Butterworth and Heinemann.

Hiler, J. (2002). Blogs as disruptive tech: How weblogs are flying under the radar of the content management giants. [viewed 30 Oct 2006, not found 7 May 2010]. http:// www.webcrimson.com/ourstories/blogsdisruptivetech.htm

Jacobs, J. (2003). Communication over exposure: The rise of blogs as a product of cybervoyeurism. Australian and New Zealand Communication Association Conference, Brisbane. [was at http:/ / www.bgsb.qut.edu.au/conferences/ANZCA03/Proceedings/papers/jjacobs _full.pdf, verified 7 May 2010 at http://joannejacobs.net/pubs/2003/ANZCA03jjacobs_full.doc]

Jensen, G., Gwyer, J., Hack, L. \& Shepard, K. (1999). Expertise in physical therapy practice. Boston: Butterworth-Heinemann.

Johnson, D., Johnson, R. \& Smith, K. (1998). Cooperative learning returns to college: What evidence is there that it works? Change, 30(4), 27-35.

Johnson, D., Maruyama, G., Johnson, R., Nelson, C. \& Skon, L. (1981). The effects of cooperative, competitive, and individualistic goal structures on achievement: A meta-analysis. Psychological Bulletin, 89, 47-62.

Johnson, D., Maruyama, G., Johnson, R., Nelson, D. \& Skon, L. (1981). Effects of cooperative, competitive, and individualistic goal structures on achievement: A meta-analysis. Psychological Bulletin, 89(1), 47-62.

Jones, M. (1992). Clinical reasoning in manual therapy. Physical Therapy, 72(12), 875-884.

Jones, M. (2003). Clinical reasoning strategies in physical therapy. Adelaide: University of South Australia.

Jones, M., Jensen, G. \& Edwards, I. (2008). Clinical reasoning in physiotherapy. In J. Higgs, M. Jones, S. Loftus \& N. Christensen (Eds), Clinical reasoning in the health professions, pp.245-256. London: Butterworth Heinemann Elsevier.

Koohang, A. (2009). A learner-centred model for blended learning design. International Journal of Innovation and Learning, 6(1), 76-91.

Ladyshewsky, R. (1993). Clinical teaching and the 2:1 student-to-clinical instructor ratio. Journal of Physical Therapy Education, 7(1), 31-35. 
Ladyshewsky, R. (1995). Enhancing service productivity in acute care inpatient settings using a collaborative clinical education model. Physical Therapy, 75, 503-510.

Ladyshewsky, R. (2002). A quasi-experimental study of the differences in performance and clinical reasoning using individual learning versus reciprocal peer coaching. Physiotherapy Theory and Practice, 18(1), 17-31.

Ladyshewsky, R. (2006). Building cooperation in peer coaching relationships: Understanding the relationships between reward structure, learner preparedness, coaching skill and learner encouragement. Physiotherapy, 92(1), 4-10.

Ladyshewsky, R. \& Gardner, P. (2008). Peer assisted learning and blogging: A strategy to promote reflective practice during clinical fieldwork. Australasian Journal of Educational Technology, 24(3), 241-257. http:/ / www.ascilite.org.au/ajet/ajet24/ladyshewsky.html

Maag, M. (2005). The potential use of "blogs" in nursing education. Computer Information Nursing, 23(1), 16-24.

McLoughlin, C. \& Lee, M. J. W. (2010). Personalised and self regulated learning in the Web 2.0 era: International exemplars of innovative pedagogy using social software. Australasian Journal of Educational Technology, 26(1), 28-43. http: / / www.ascilite.org.au/ajet/ajet26/mcloughlin.html

Mongkolwat, P., Kogan, A., Koh, J. \& Channin, D. (2005). Blogging your PACS. Journal of Digital Imaging, 18(4), 326-332.

Mouhtouris, A. (2006). All about e-learning with Nigel Paine. Campus Review, 8 March. [verified 8 May 2010] http: / / www.aesharenet.com.au / Nigel $\% 20$ Paine $\% 20$ interview $\% 20$ in $\% 20$ Campus\%20Review\%208\%20March\%202006.pdf

Plutchak, T. (2005). I see blog people. Journal of Medical Library Association, 93(3), 305-307.

Qin, Z., Johnson, D. \& Johnson, R. (1995). Cooperative versus competitive efforts and problem solving. Review of Educational Research, 65(2), 129-143.

Refshauge, K. \& Higgs, J. (2000). Teaching clinical reasoning. In J. Higgs \& M. Jones (Eds), Clinical reasoning in the health professions, pp.141-147. Oxford: Butterworth-Heinemann.

Sauer, I., Bialek, D., Efimoya, E., Schwartlander, R., Pless, G. \& Neuhaus, P. (2005). "Blogs" and "wikis" are valuable software tools for communication within research groups. Artificial Organs, 29(1), 82-83.

Schmidt, H. \& Boshuizen, H. (1993). On acquiring expertise in medicine. Educational Pyschological Review, 5(3), 205-221.

Thornquist, E. (2001). Diagnostics in physiotherapy - processes, patterns and perspectives. Advances in Physiotherapy, 3, 151-162.

Topping, K. (1992). Cooperative learning and peer tutoring: An overview. Psychologist, 5, 151161.

Ms Shuyan Melissa Tan, Richard K. Ladyshewsky and Peter Gardner

Curtin University of Technology, Perth, Western Australia

Corresponding Author: Richard K. Ladyshewsky

Email: Rick.Ladyshewsky@gsb.curtin.edu.au 